\title{
CENTROS DE PARTO NORMAL: REVISÃO INTEGRATIVA
}

Jaqueline Carine Nicaretta

Discente do Curso de Enfermagem da Universidade Paranaense - UNIPAR, Toledo (PR), Brasil.

Daiane Tofoli Cortêz

Docente do Curso de Enfermagem da Universidade Paranaense - UNIPAR, Toledo (PR), Brasil.

E-mail: daianecortez@unipar.br
RESUMO: Este artigo objetivou identificar a produção científica brasileira existente sobre a assistência nos Centros de Parto Normal e seus benefícios. Trata-se de um trabalho de revisão integrativa, realizado através das bases de dados eletrônicas e portais de periódicos: Periódicos CAPES, biblioteca eletrônica SCIELO e Google Acadêmico. A consulta dos artigos foi realizada no período de junho a agosto de 2014, por intermédio de pesquisa on-line, sendo selecionados sete artigos, os quais atenderam aos critérios de inclusão. Verifica-se que os artigos publicados buscam identificar e descrever os resultados obtidos pela assistência nos CPN à mãe e ao bebê, além da satisfação das mesmas nestes serviços. Observou-se que os CPN oferecem atendimento digno à mãe, à criança e à toda a família, reduzindo às práticas, medicamentos, as intervenções desnecessárias no parto e também as complicações, além de trazer conforto, segurança e bem-estar à gestante e ao recém-nascido mediante ao atendimento humanizado e de qualidade realizado pelos profissionais, principalmente os enfermeiros. É possível perceber também uma diminuição das taxas de cesáreas onde foram implantados os CPN, e maior satisfação das mulheres atendidas, onde as mesmas possuem autonomia no seu trabalho de parto, além de todo apoio oferecido pelos familiares e enfermeiros durante todo o processo no nascimento. Portanto, destaca-se o enfermeiro como um profissional fundamental nesta assistência realizada às parturientes, prestando atendimento de qualidade, além de dar apoio e transmitir segurança às mulheres.

PALAVRAS-CHAVE: Parto Humanizado; Parto Normal.

\section{CENTERS FOR NORMAL BIRTH DELIVERY: INTEGRATION REVISION}

ABSTRACT: Current analysis identifies Brazilian scientific production on birth delivery in a Center for Normal Birth and its benefits. The paper comprises integration revision from electronic bases and journal: CAPES journals, SciELO electronic library and Academic Google. Articles were accessed between June and August 2014 and seven were selected due to inclusion criteria. Articles try to identify and describe results from assistance to mother and child in $\mathrm{CNB}$, coupled to their satisfaction with the services. CNB offers a service which dignifies the mother, child and the family, through the reduction of practices, drugs and unnecessary interventions in birth, coupled to the avoidance of complications and the addition of comfort, safety and welfare to the mother and newly-born child. The above occurred due to humanized attendance and excellent service quality by professionals, especially nurses. Decrease in caesarian operations occurred where CNB was introduced, with great satisfaction to the mother attended. In fact, they have autonomy in birth, besides the support by family, kin and nurses during the birthing process. In fact, nurses are basic in such assistance, with their quality attendance and assurance to pregnant females. 
KEY WORDS: Humanized Delivery; Normal Birth.

\section{INTRODUÇÃO}

O parto não intervencionista foi por muito tempo considerado uma prática comum na sociedade. Porém, a partir do século $\mathrm{XX}$, a medicina tornou este momento que era considerado algo fisiológico, em um momento patológico, necessitando muitas vezes de tratamento medicamentoso e cirúrgico, tornando a assistência ao parto exclusivamente hospitalar (CRIZÓSTOMO; NERY; LUZ, 2007).

Apesar dos benefícios da institucionalização, o trabalho de parto hospitalar tornou-se algo técnico, impessoal, com pouca afetividade, ocasionando assim a exclusão da família e tornando esse momento singular em uma experiência sofrida e fria, na qual a mulher muitas vezes é tratada como um simples objeto (CECAGNO; ALMEIDA, 2004).

Tornquist (2002) ressalta que a medicina, com altas tecnologias, transformou o parto e o nascimento que seria um momento natural em um momento complexo e patológico, tornando-se excessiva a medicalização, as cesáreas e demais intervenções cirúrgicas na assistência ao parto.

Frente a isto, a Organização Mundial de Saúde (OMS) recomenda mudanças no atendimento hospitalar medicalizado e muitas vezes abusivo, sugerindo o incentivo ao parto normal com atuação de enfermeiras obstétricas, presença de acompanhante no processo de parto, aleitamento materno, parteiras nos locais onde a instituição hospitalar não esteja presente pelo sistema de saúde. Sugerem ainda, mudanças nas rotinas hospitalares visando diminuir as intervenções desnecessárias que podem gerar riscos à mãe e ao bebê como a realização de episiotomia, tricotomia, enema, amniotomia e partos cesáreas, devendo ser realizadas apenas quando comprovada a necessidade (TORNQUIST, 2002).

Porém, mesmo diante das recomendações da OMS, é possível perceber uma elevada incidência de cesáreas no Brasil, pois de acordo com a OMS a taxa ideal de cesáreas está entre 10 a 15\%, entretanto, de acordo com os dados disponibilizados pelo Ministério da Saúde no Sistema de Informação dos Nascidos Vivos (SINASC), a taxa de cesáreas no Brasil em 2011 foi de 53,88\% (BRASIL, 2011). O aumento desta prática pode estar relacionado com a preferência médica, visto que acontece como uma intervenção programada, com horário delimitado, diferentemente do parto normal que é imprevisível podendo ocorrer a qualquer momento, como finais de semana e feriados, levando ainda algumas horas para evoluir (FAÚNDES; CECATTI, 1991).

Deste modo, percebemos que muitas vezes o desejo da mulher e a humanização na assistência são esquecidos, prevalecendo assim a vontade da equipe de saúde. Portanto Silva et al. (2008) ressaltam que:

\begin{abstract}
Enfrentar o desafio de reduzir as taxas de cesarianas não é simplesmente resolver uma questão numérica. Também é fundamental almejar uma assistência humanizada ao nascimento e ao parto e isso significa um tipo de assistência que, indo além de apenas buscar o parto normal a qualquer custo, procure resgatar a posição central da mulher no processo do nascimento. Uma assistência que respeite a dignidade das mulheres, sua autonomia e autoria (SILVA et al., 2008, p. 2).
\end{abstract}

Com o intuito de resgatar o parto normal e prestar uma assistência digna e humanizada às gestantes, vêm sendo instituídos no país desde a década de 90 , os Centros de Parto Normal, que constituem um novo modelo de assistência obstétrica, seguindo recomendações da OMS onde os profissionais estão voltados para a gestante e sua família (MACHADO; PRAÇA, 2006). Porém, essas mudanças estão acontecendo lentamente e enfrentam a resistência do modelo médico, estabelecido em condutas historicamente intervencionistas (SCHNECK; RIESCO, 2006).

Brasil (1999) salienta que os Centros de Parto Normal (CPN) foram criados no Brasil através da Portaria do Ministério da Saúde $n^{0}$ 985/GM, em 05 de agosto de 1999, a fim de garantir a universalidade de acesso à assistência ao parto, oferecendo uma assistência humanizada durante a gravidez, ao parto e puerpério, reduzindo consequentemente a taxa de mortalidade materna e perinatal. 
Vale destacar que os Centros de Parto Normal surgiram com o objetivo de resgatar o direito à privacidade e à dignidade da mulher ao dar à luz num local semelhante ao seu ambiente familiar, e ao mesmo tempo garantir segurança à mãe e seu filho, oferecendo-lhes recursos tecnológicos apropriados em casos de eventual necessidade. Seguem um padrão de procedimentos previamente estabelecidos e que direcionam as ações que realizam (MACHADO; PRAÇA, 2006, p. 275).

Observa-se que a criação dos CPN busca resgatar a prática do parto normal que possui vantagens tanto para a mãe quanto para o bebê, como a rápida recuperação pós-parto, baixo risco de infecção, hemorragias e outras complicações, além de ambos receberem alta precocemente (LEGUIZAMON JUNIOR; STEFFANI; BONAMIGO, 2013).

De acordo com Brasil (1999), "Entende-se como Centro de Parto Normal a unidade de saúde que presta atendimento humanizado e de qualidade exclusivamente ao parto normal sem distócias".

Esses CPNs são estabelecimentos que pertencem ao hospital e realizam assistência ao parto de baixo risco, podendo ser instalados nas dependências internas do ambiente hospitalar, sendo classificados como Centro de Parto Normal Intra-hospitalar - CPNi, ou podem ser localizados nas dependências externas, devendo estar no máximo 200 metros de distância do ambiente hospitalar, denominados de Centro de Parto Normal Peri-hospitalar - CPNp (BRASIL, 2013).

Dentre as atribuições dos CPNs, Brasil (1999) ressalta as atividades educativas voltadas ao preparo da gestante para o trabalho de parto e amamentação; acolhimento e avalição das gestantes; presença de acompanhante; avaliação fetal através do partograma e exames complementares; garantia de assistência centrada na parturiente, com respeito à sua individualidade, garantindo um parto normal sem distócias; garantia de assistência ao recém-nascido sem alterações e atendimento imediato ao recém-nascido com riscos potenciais; garantia de transporte da gestante e criança em casos de necessidade de encaminhamento; acompanhamento e monitoramento do puerpério por no mínimo 10 dias; realização de ações conjuntas com unidades de saúde de referência e/ou programas de saúde da família e agentes comunitários.

Em relação aos profissionais habilitados para atuar no CPN, a Resolução COFEN no 308/2006 estabelece que os CPNs devam possuir no mínimo uma equipe composta por um enfermeiro obstetra coordenador, um enfermeiro assistencial que tenha especialização em obstetrícia, um técnico de enfermagem, um auxiliar de enfermagem, um auxiliar de serviços gerais e um motorista de ambulância por período de funcionamento, entretanto, a quantidade de profissionais deve estar de acordo à demanda do atendimento, sendo necessário o dimensionamento de pessoal conforme as necessidades da instituição, além disso, os CPNs autônomos devem possuir um médico obstetra e um médico neonatalogista.

Diante disto, verificamos que o enfermeiro é um profissional essencial nos CPNs, sendo ele responsável em acolher a gestante, realizar atividades voltadas para a necessidade da parturiente e família, garantindo um atendimento humanizado e de qualidade, sem distócias, respeitando a individualidade da gestante e priorizando atividades menos invasivas (COFEN, 2006).

Frente ao exposto, este artigo objetivou identificar a produção científica brasileira existente sobre a assistência nos CPNs e seus benefícios.

\section{METODOLOGIA}

Trata-se de um artigo científico de revisão integrativa, realizado por meio das bases de dados eletrônicas e portais de periódicos: Periódicos CAPES, biblioteca eletrônica SciELO (Scientific Eletronic Library Online) e Google Acadêmico.

Mendes, Silveira e Galvão (2008) destacam que a revisão integrativa permite a avaliação crítica e uma análise ampla da literatura, realizando assim uma síntese das evidências disponíveis em relação ao tema pesquisado, podendo enfatizar as intervenções efetivas na assistência à saúde, como identificar lacunas a fim de orientar o desenvolvimento de pesquisas futuras.

Diante disto, a questão norteadora deste trabalho foi "O que tem sido publicado na produção 
científica brasileira em relação à assistência nos Centros de Parto Normal e seus benefícios?". Para o levantamento dos artigos foram utilizados os descritores em ciências da saúde - DeCS da BVS-BIREME: parto normal; parto humanizado e centros independentes de assistência à gravidez e ao parto.

A consulta dos artigos foi realizada no período de junho a agosto de 2014, por intermédio de pesquisa on-line. $\mathrm{O}$ acesso às publicações na íntegra se deu a partir dos portais SciELO.

Como critério de inclusão foram utilizados: artigos originais, teses, dissertações indexados nas bases de dados referidas entre 2004 a 2013, escritos em português, disponíveis gratuitamente na íntegra e que respondessem a questão norteadora. Utilizando o cruzamento dos descritores nas bases de dados supracitadas, foram encontrados 152 artigos, sendo selecionados 07 artigos, os quais atenderam aos critérios de inclusão.

\section{RESULTADOS E DISCUSSÃO}

Foram selecionados para fazer parte desta revisão integrativa sete artigos que atenderam ao objetivo proposto. Os artigos foram codificados em B1 a B7, conforme o ano de publicação. Todos os artigos foram publicados no Brasil, e escritos por autores enfermeiros, o que evidencia a importância deste profissional no CPN, além da sua preocupação no atendimento humanizado e de qualidade.

Assim, com intuito de verificar o ano e a revista de publicação dos artigos, bem como identificar os autores, foi realizado o Quadro 1.

Quadro 1. Distribuição dos artigos segundo autores, ano de publicação e periódico de 2004 a 2013

\begin{tabular}{|l|c|c|l|}
\hline \multicolumn{1}{|c|}{ Autores } & $\begin{array}{c}\text { Artigo/ } \\
\text { Código }\end{array}$ & $\begin{array}{c}\text { Ano } \\
\text { Publicação }\end{array}$ & \multicolumn{1}{c|}{ Periódico } \\
\hline MACHADO, N. X. S.; PRAÇA, N. S. & B1 & 2004 & Revista Escola de Enfermagem USP \\
\hline HOGA, L. A. K. & B2 & 2004 & Revista Brasileira de Enfermagem REBEN \\
\hline CAMPOS, S. E. V.; LANA, F. C. F. & B3 & 2007 & Caderno Saúde Pública \\
\hline LOBO, S. F. et al. & B4 & 2009 & Revista Escola de Enfermagem USP \\
\hline RIESCO, M. L. G. et al. & B5 & 2009 & Revista Escola de Enfermagem USP \\
\hline SCHNECK, C. A. et al. & B6 & 2012 & Revista de Saúde Pública \\
\hline JAMAS, M. T.; HOGA, L. A. K.; REBERTE, L. M. & B7 & 2013 & Caderno Saúde Pública \\
\hline
\end{tabular}

Fonte: Autora (2014).

De acordo com o Quadro 1, o periódico que apresentou maior contribuição para a pesquisa foi a Revista Escola de Enfermagem USP, e os anos de maiores publicações foram 2004 e 2009. Verifica-se que a revista mais escolhida para publicação do artigo foi na área da enfermagem, o que pode estar relacionado ao fato dos autores serem enfermeiros.

A seguir o Quadro 2 foi criado para apresentar a classificação dos periódicos, onde os artigos foram publicados conforme o Qualis CAPES.

Quadro 2. Classificação dos periódicos conforme o Qualis CAPES.

\begin{tabular}{|l|c|}
\hline Nome do Periódico & Qualis Capes \\
\hline Revista Escola de Enfermagem USP & A2 \\
\hline Revista Brasileira de Enfermagem REBEN & A2 \\
\hline Caderno Saúde Pública & A2 \\
\hline Revista de Saúde Pública & A2 \\
\hline
\end{tabular}

Fonte: Qualis CAPES (2014). 
Frente ao Quadro 2, percebe-se que todos os periódicos nos quais os artigos foram publicados possuem o Qualis CAPES A2. Assim, evidencia-se que os artigos foram publicados em periódicos que possuem um nível elevado de classificação pela CAPES, sendo considerados ótimos periódicos, demonstrando, dessa forma, a preocupação dos enfermeiros não apenas em realizar a pesquisa, mas também em publicá-la em um periódico com ótima classificação.

A Coordenação de Aperfeiçoamento de Pessoal de Nível Superior (CAPES) é responsável pelo Qualis
CAPES, que é denominado como um conjunto de procedimentos realizados com finalidade de avaliar os periódicos, que são classificados em A1, relacionado ao nível mais elevado, sendo seguido por A2, B1, B2, B3, B4, B5 e C, com peso zero (CAPES, 2014).

Com a finalidade de facilitar e proporcionar uma melhor análise dos dados representados pelos artigos foi elaborado o Quadro 3, o qual identifica o título do artigo, tipo de estudo, objetivos e os resultados e/ou conclusão.

\section{Quadro 3. Identificação dos artigos.}

(continua)

\begin{tabular}{|c|c|c|}
\hline Título/Código/Tipo Estudo & Objetivo(s) & Resultados/Conclusões \\
\hline $\begin{array}{l}\text { Centro de parto normal e assistência } \\
\text { obstétrica centrada nas necessidades } \\
\text { da parturiente. / B1 / Pesquisa } \\
\text { exploratória. }\end{array}$ & $\begin{array}{l}\text { - Propor a substituição da expressão } \\
\text { "assistência humanizada ao parto" por } \\
\text { "assistência obstétrica centrada nas } \\
\text { necessidades da parturiente" e relatar } \\
\text { como essa assistência é prestada no } \\
\text { CPN do Hospital Geral de Itapecerica } \\
\text { da Serra (SP). }\end{array}$ & $\begin{array}{l}\text { Os Centros de Parto Normal constituem-se em ricas } \\
\text { experiências assistenciais e de ensino, tanto para } \\
\text { os profissionais quanto para as mulheres, estas por } \\
\text { sua vez são as maiores beneficiadas onde possuem } \\
\text { autonomia, e recebem assistência humanizada, voltada } \\
\text { para sua real necessidade. }\end{array}$ \\
\hline $\begin{array}{l}\text { Casa de parto: simbologia e princípios } \\
\text { assistenciais. / B2 / Etnografia e história } \\
\text { oral temática. }\end{array}$ & $\begin{array}{l}\text { - Identificar símbolos que permeiam as } \\
\text { ideias, crenças, valores e práticas e os } \\
\text { princípios que orientam a assistência } \\
\text { prestada na Casa de Parto. }\end{array}$ & $\begin{array}{l}\text { O preparo e o grande envolvimento dos profissionais } \\
\text { da casa de parto mostra com grande evidência que as } \\
\text { mesmas prestam o cuidado às mulheres com qualidade; } \\
\text { a essência do cuidado está centrada na pessoa, } \\
\text { considerada como um ser humano que vem de um } \\
\text { ambiente físico, social e simbólico com preocupação } \\
\text { voltada ao conhecimento de suas particularidades e } \\
\text { atendimento destas no seu processo de gestar e dar } \\
\text { a luz. }\end{array}$ \\
\hline $\begin{array}{l}\text { Resultados da assistência ao Centro de } \\
\text { Parto Normal Dr. David Capistrano da } \\
\text { Costa Filho em Belo Horizonte, Minas } \\
\text { Gerais, Brasil./ B3 / Pesquisa descritiva } \\
\text { e retrospectiva. }\end{array}$ & $\begin{array}{l}\text { - Descrever e discutir os resultados } \\
\text { dos indicadores clínicos referentes à } \\
\text { assistência realizada em um CPN de } \\
\text { Belo Horizonte. }\end{array}$ & $\begin{array}{l}\text { A implantação de um CPN é uma estratégia importante } \\
\text { e essencial na assistência ao parto, visto que contribui } \\
\text { tanto para a experiência inovadora para enfermeiros } \\
\text { obstetras e profissionais da área hospitalar de } \\
\text { referência, como para a redução do número de } \\
\text { cesáreas. }\end{array}$ \\
\hline $\begin{array}{l}\text { Resultados maternos e neonatais em } \\
\text { Centro de Parto Normal peri-hospitalar } \\
\text { na cidade de São Paulo, Brasil./ B4 / } \\
\text { Pesquisa descritiva e retrospectiva. }\end{array}$ & $\begin{array}{l}\text { - Descrever resultados maternos e } \\
\text { perinatais da assistência no centro de } \\
\text { parto normal peri-hospitalar. }\end{array}$ & $\begin{array}{l}\text { O CPN possui uma estrutura física e técnico- } \\
\text { administrativa que favorece um cuidado mais centrado } \\
\text { nas necessidades escolhas da mulher. Observou-se que } \\
\text { as mães atendidas pelas enfermeiras obstetras no CPN } \\
\text { possuem menor chance de serem hospitalizadas, ou } \\
\text { submetidas a procedimentos invasivos desnecessários. } \\
\text { Estas podem então terem o parto vaginal espontâneo, } \\
\text { possuir controle da situação desde o nascimento até o } \\
\text { momento da amamentação. }\end{array}$ \\
\hline $\begin{array}{l}\text { Centros de Parto Normal no Brasil: } \\
\text { revisão da produção científica. / B5 / } \\
\text { Revisão narrativa. }\end{array}$ & $\begin{array}{l}\text { - Identificar a produção científica } \\
\text { brasileira relacionada ao processo } \\
\text { assistencial e aos resultados maternos } \\
\text { e perinatais no CPN. }\end{array}$ & $\begin{array}{l}\text { As pesquisas brasileiras sobre CPN são realizadas } \\
\text { geralmente por enfermeiras obstetras atuantes no } \\
\text { serviço ou docentes pesquisadores. De acordo com } \\
\text { o estudo realizado, verificou-se que nos CPNs a } \\
\text { assistência é voltada às gestantes, preconizando o } \\
\text { parto normal sem distócias, com redução de práticas } \\
\text { invasivas e incentivo à deambulação, e ações não } \\
\text { farmacológicas que aliviam a dor. }\end{array}$ \\
\hline
\end{tabular}


(conclusão)

\begin{tabular}{|l|l|l|}
\hline $\begin{array}{l}\text { Resultados maternos e neonatais em } \\
\text { centro de parto normal peri-hospitalar } \\
\text { e hospital. / B6 / Estudo transversal. }\end{array}$ & $\begin{array}{l}\text { - Comparar os resultados maternos e } \\
\text { neonatais em mulheres de baixo risco } \\
\text { atendidas em centro de parto normal } \\
\text { peri-hospitalar e hospital. }\end{array}$ & $\begin{array}{l}\text { A assistência realizada no CPN apresentou menos } \\
\text { intervenções do que o ambiente hospitalar, realizando } \\
\text { um atendimento humanizado à gestante e à família. }\end{array}$ \\
\hline $\begin{array}{l}\text { Narrativas de mulheres sobre a } \\
\text { assistência recebida em um Centro de } \\
\text { Parto Normal / B7 / Pesquisa Narrativa. }\end{array}$ & $\begin{array}{l}\text { - Avaliar o que as mulheres relataram } \\
\text { da assistência recebida em um CPN. }\end{array}$ & $\begin{array}{l}\text { As mulheres apresentaram grande satisfação com } \\
\text { o atendimento recebido no CPN, informação que } \\
\text { confirma as premissas de vários pesquisadores de que } \\
\text { o atendimento e a estrutura possui grande influência } \\
\text { no trabalho de parto. }\end{array}$ \\
\hline
\end{tabular}

Fonte: Autora (2014).

Frente aos quadros acima, observa-se que dentre os sete artigos que atenderam aos critérios propostos, seis foram trabalhos de pesquisa, dos quais dois foram de pesquisa descritiva e retrospectiva, seguidos igualmente com um trabalho cada às pesquisas: exploratória, narrativa, etnográfica e estudo transversal. Apenas um artigo foi de revisão narrativa.

Dos seis artigos de pesquisa avaliados, todos foram desenvolvidos em Centros de Parto Normal, sendo dois realizados em CPN peri-hospitalar, um em CPN intrahospitalar, e os outros não realizaram a classificação do CPN, além disso um dos trabalhos foi realizado no CPN e no ambiente hospitalar.

Os artigos publicados buscam identificar e descrever os resultados obtidos pela assistência nos CPNs à mãe e ao bebê, além da satisfação das mesmas nestes serviços. Desse modo, verifica-se uma preocupação em identificar como está sendo realizada a assistência à mulher e ao recém-nascido, nesses novos estabelecimentos de saúde, e em avaliar se esses CPNs estão prestando assistência humanizada e de qualidade, conforme é preconizado pelo Ministério da Saúde e OMS.

É realçado no artigo B1 que um dos principais objetivos dos CPNs é resgatar o direito à privacidade e à dignidade da paciente, no qual poderá dar a luz ao seu filho em um lugar semelhante ao ambiente familiar, e ao mesmo tempo garantir segurança no atendimento, além da disponibilidade de recursos tecnológicos apropriados.

Ainda no mesmo artigo é possível identificar que no CPN a assistência prestada é centrada nas necessidades das parturientes, onde as mesmas possuem autonomia, direito ao acompanhante, liberdade de locomoção durante o trabalho de parto, decisão sobre o momento da realização do exame tocoginecológico. A família é encorajada a estar próxima da parturiente, sendo autorizado fotografar o trabalho de parto, eternizando este momento único. Além disso, verifica-se o respeito dos profissionais com a parturiente, adoção de medidas não farmacológicas para o alívio da dor, estímulo do contato da mãe com o bebê logo após o nascimento, incentivo ao acompanhante seccionar o cordão umbilical proporcionando um vínculo do mesmo com o bebê e a promoção de ações de apoio ao aleitamento materno imediato.

Corroborando isto, o artigo B4 enfatiza em sua pesquisa que o CPN atende às recomendações da OMS, prestando assistência humanizada às parturientes, que relataram grande satisfação pelo atendimento recebido. $\mathrm{O}$ artigo identificou que no CPN há uma redução significativa de utilização de fármacos, de procedimentos invasivos como a episiotomia, e as mulheres atendidas apresentaram menos lacerações durante o trabalho de parto devido ao preparo e às orientações que as gestantes tiveram durante a gravidez. Em relação ao recém-nascido, a maioria não necessitou de atendimento hospitalar, nasceram com dados vitais adequados, sendo que logo após o nascimento já tiveram contato com as mães.

Reforçando os achados anteriores, o artigo B6, ao comparar a assistência realizada no CPN e no ambiente hospitalar, constatou que o hospital apresenta um índice elevado de alterações dos recém-nascidos, como desconforto respiratório necessitando de internação em unidade de terapia intensiva (UTI) neonatal e valor do Apgar diferente dos valores do CPN, além da utilização de fármacos no pré e pós-parto, uso de episiotomia, hemorragia uterina, aspiração nasal e gastrointestinal do recém-nato. Esta comparação ressalta a importância dos CPNs no atendimento humanizado, centrado 
nas necessidades maternas e neonatais, reduzindo consequentemente os procedimentos invasivos $\mathrm{e}$ desnecessários, além de incentivar o parto natural.

$\mathrm{O}$ artigo B2 enfatiza que os CPNs estão voltados para uma assistência humanizada, visando à melhoria da qualidade do atendimento à gestante e sua família. Neste entendimento, a gestante é considerada o centro do processo, e as enfermeiras realizam atendimento mantendo a preocupação constante em realizar assistência com qualidade, respeitando a liberdade e a autonomia da mulher além de proporcionar um ambiente de carinho e hospitalidade à família e à gestante, a fim de promover um ambiente favorável ao parto. Neste trabalho, as enfermeiras participantes do estudo relataram o orgulho e a satisfação por atuarem nos CPNs, afirmando que estão ganhando seu espaço na área profissional e possuindo autonomia para realização dos procedimentos embasados em protocolos.

$\mathrm{O}$ artigo $\mathrm{B} 7$ ressalta que as mulheres participantes da pesquisa, ao expressarem sua opinião sobre os CPNs, relataram ter sido bem acolhidas e assistidas, que os profissionais sempre estão dando apoio e orientações sobre o trabalho de parto, além de apresentar medidas alternativas para aliviar a dor e ajudar na evolução do parto como: sentar na bola, caminhar, tomar banho no chuveiro, visando assim à qualidade e ao bem-estar da parturiente.

$\mathrm{O}$ artigo B3 destaca a importância do CPN para a redução dos níveis de cesáreas desnecessárias, sendo uma estratégia eficaz para a promoção do parto normal e a redução dos casos de cesáreas como preconizados pela OMS. O artigo aponta ainda como ponto positivo do CPN intra-hospitalar a não necessidade de transferência da mãe e do recém-nascido para o ambiente hospitalar, visto que o mesmo já se encontra dentro do âmbito hospitalar, o que difere do CPN extra-hospitalar que necessita realizar o transporte para o serviço de referência.

Todos os artigos analisados evidenciam a importância da enfermeira obstetra no CPN, e os artigos B1 e B5 ressaltam que a enfermeira obstetra é essencial na assistência prestada no CPN, entretanto, deve possuir um amplo conhecimento sobre a assistência humanizada às gestantes, a fim de prestar um atendimento voltado às reais necessidades da parturiente, dando apoio e orientações, além de promover sua autonomia e informar também os familiares sobre os cuidados e a evolução do trabalho de parto da parturiente, realizando assim um atendimento voltado à família e à gestante. $\mathrm{O}$ artigo $\mathrm{B} 4$ destaca que no CPN estudado a enfermeira obstetra possui total autonomia e é responsável pelas decisões referentes ao cuidado à mulher e ao bebê, sendo respaldada por protocolos assistenciais.

Ainda referente ao cuidado realizado pela enfermeira, o artigo B6 enfatiza que o acompanhamento contínuo da enfermagem foi apontado pelas mães como sinônimo de atenção, pois é neste momento que a parturiente necessita de apoio, segurança, orientação e informações sobre a evolução do trabalho de parto, portanto esse tipo de atendimento gerou sentimento positivo, como satisfação, tranquilidade, bem-estar e segurança, evitando assim a solidão e reduzindo a preocupação da mesma.

Verifica-se que os CPNs estudados seguem as recomendações da OMS, prestando atendimento integral e humanizado à mulher e ao bebê, oferecendo apoio emocional à paciente, orientações sobre o trabalho de parto, pós-parto, amamentação e cuidados com o recémnascido, informação ao acompanhante, sobre seu papel durante a evolução do trabalho de parto, bem como para a família, que deve sempre estar dando apoio à parturiente e à criança, além disso, enfatizam a importância do contato direto do recém-nascido (RN) com a mãe logo após o nascimento, e a redução de práticas invasivas e medicalizadas, tornando assim o momento do parto um processo natural e significante para a mulher e sua família. Os artigos expõem ainda a satisfação das mulheres na assistência realizada pelos CPNs, bem como a autonomia que é dada a elas durante o trabalho de parto.

\section{CONCLUSÃO}

Diante da revisão integrativa realizada, observou-se que os Centros de Parto Normal atendem às recomendações da OMS em oferecer assistência humanizada e centrada nas necessidades da parturiente, no entanto, os mesmos estão sendo implantados vagarosamente no Sistema Único de Saúde brasileiro. 
Verificou-se que os Centros de Parto Normal oferecem atendimento digno à mãe, à criança e à toda a família, reduzindo as práticas medicamentosas, as intervenções desnecessárias no parto e também as complicações, além de trazer conforto, segurança e bem-estar à gestante e ao recém-nascido mediante ao atendimento humanizado e de qualidade realizado pelos profissionais, principalmente os enfermeiros.

Percebeu-se uma diminuição das taxas de cesáreas onde foram implantados os CPNs, e maior satisfação das mulheres atendidas, no qual possuem autonomia no seu trabalho de parto, além de todo apoio oferecido pelos familiares e enfermeiros durante toda evolução do trabalho de parto.

Observamos também que o profissional enfermeiro tem um papel fundamental na assistência realizada às parturientes nos $\mathrm{CPNs}$, ao prestar atendimento humanizado e de qualidade, apoiando e transmitindo segurança às mulheres, além de demonstrarem preocupação com a qualidade desta assistência por meio de estudos e pesquisas sobre o assunto.

Apesar de alguns profissionais ainda apresentarem resistência com relação a esse novo modelo de assistência ao parto, percebe-se que aos poucos ele está sendo implantado e os estudos já publicados contribuem para a informação e a sensibilização da comunidade sobre a importância do modelo de assistência CPN, que traz benefícios para a mãe, o bebê e a toda família.

\section{REFERÊNCIAS}

BRASIL. Ministério da Saúde. Portaria no 904, de 29 de maio de 2013. Estabelece diretrizes para implantação e habilitação de Centro de Parto Normal (CPN), no âmbito do Sistema Único de Saúde (SUS), para o atendimento à mulher e ao recém-nascido no momento do parto $\mathrm{e}$ do nascimento, em conformidade com o Componente parto e nascimento da Rede Cegonha, e dispõe sobre os respectivos incentivos financeiros de investimento, custeio e custeio mensal. Brasília: 2013. Disponível em: <http://bvsms.saude.gov.br/bvs/saudelegis/gm/2013/ prt0904_29_05_2013.html >. Acesso em: 05 maio 2014.
BRASIL. Ministério da Saúde. Portaria no 985/GM Em 05 de agosto de 1999. Cria o Centro de Parto NormalCPN, no âmbito do Sistema Único de Saúde. Brasília: 1999. Disponível em: < http://tr2001.saude.gov.br/sas/ PORTARIAS/Port99/GM/GM-0985.html>. Acesso em: 25 abr. 2014.

BRASIL. Ministério da Saúde. Sistema de Informação sobre Nascidos Vivos - SINASC. Brasília: 2011. Disponível em: <http://tabnet.datasus.gov.br/cgi/tabcgi. exe?idb2012/f08.def> . Acesso em: 21 maio 2014.

CAMPOS, S. E. V.; LANA, F. C. F. Resultados da assistência ao parto no Centro de Parto Normal Dr. David Capistrano da Costa Filho em Belo Horizonte, Minas Gerais, Brasil. Cad Saúde Pública, Rio de Janeiro, v. 23, n. 6, p. 13491359, 2007. Disponível em: < http://www.scielosp.org/ pdf/csp/v23n6/09.pdf> . Acesso em: 01 jul. 2014.

CECAGNO, S.; ALMEIDA, F. D. O. Parto domiciliar assistido por parteiras em meados do século XX numa ótica cultural. Texto Contexto Enferm, v. 13, n. 3, p. 409-413, jul./set. 2004. Disponível em: < http://www. scielo.br/pdf/tce/v13n3/a10v13n03.pdf > . Acesso em: 19 maio 2014 .

COFEN. Resolução COFEN No 308/2006. Constituição Federativa do Brasil, promulgada em 05 de outubro de 1988, em seus artigos $5^{\circ}$, XII que trata dos direitos e garantias fundamentais e art. 197. 2006. Disponível em: $\quad<$ http://www.coren-df.gov.br/portal/index.php/ resolucoes/322-resolucao-cofen-no-3082006> Acesso em: 22 set. 2014.

COORDENAÇÃO DE APERFEIÇOAMENTO DE PESSOAL DE NÍVEL SUPERIOR - CAPES. Qualis Periódicos. 2014. Disponível em: <http://qualis.capes.gov.br/webqualis/ principal.seam > . Acesso em: 19 maio 2014.

CRIZOSTOMO, C. D.; NERY, I. S.; LUZ, M. H. B. A vivência de mulheres no parto domiciliar e hospitalar. Esc Anna Nery R Enferm, v. 11, n. 1, p. 98-104, mar. 2007. Disponível em: <http://www.scielo.br/pdf/ean/v11n1/ v11n1a14.pdf > . Acesso em: 19 maio 2014. 
FAÚNDES, A.; CECATTI, J. G. A operação Cesárea no Brasil. Incidência, tendências, causas, consequências e propostas de ação. Cad. Saúde Pública, Rio de Janeiro, v. 7, n. 2, 1991. Disponível em: < http://www.scielo.br/scielo. php? pid $=$ S0102-311X1991000200003\&script $=$ sci arttext\&tlng $=\mathrm{pt}>$. Acesso em: 14 jun. 2014.

HOGA, L. A. K. Casa de parto: simbologia e princípios assistenciais, Rev Bras Enferm., Brasília, v. 57, n. 5, 2004. Disponível em: <http://www.scielo. $\mathrm{br} /$ scielo.php? script $=$ sci_arttext $\&$ pid $=S 0034$ $71672004000500004 \& \operatorname{lng}=$ en\&nrm $=i s o \& t \operatorname{lng}=p t>$. Acesso em: 03 jul. 2014.

JAMAS, M. T.; HOGA, L. A. K.; REBERTE, L. M. Narrativas de mulheres sobre a assistência recebida em um centro de parto normal, Cad Saúde Pública, Rio de Janeiro, v. 29, n. 2, 2013. Disponível em: < http://www. scielo.br/scielo.php?script $=$ sci_arttext $\&$ pid $=S 0102$ 311X2013001200009\&lang $=\mathrm{pt}>$. Acesso em: 02 jul. 2014.

LEGUIZAMON JUNIOR, T. L.; STEFFANI, J. A.; BONAMIGO, E. L. Escolha da via de parto: expectativa das gestantes e obstetras. Rev Bioét., Brasília, v. 21, n. 3, set./dec. 2013. Disponível em: <http://www. scielo.br/scielo.php?script $=$ sci_arttext\&pid $=$ S1983$80422013000300015 \&$ lang $=p t>$. Acesso em: 14 jun. 2014 .

LOBO, S. F.; OLIVEIRA, S. M. J. V.; SCHNECK, C. A.; SILVA, F. M. B.; BONADIO, I. C.; RIESCO, M. L. G. Resultados maternos e neonatais em Centro de Parto Normal peri-hospitalar na cidade de São Paulo, Brasil. Rev Esc Enferm USP, v. 44, n. 3, p. 812-818, 2009. Disponível em: <http://www.scielo.br/pdf/reeusp/v44n3/37.pdf > . Acesso em: 01 jul. 2014.

MACHADO, N. X. S.; PRAÇA, N. S. Centro de parto normal e assistência obstétrica centrada nas necessidades da parturiente. Rev Esc Enferm USP, v. 40, n. 2, p. 274-279, 2006. Disponível em: < http://www.scielo.br/pdf/reeusp/ v40n2/16.pdf>. Acesso em: 28 abr. 2014.
Revisão integrativa: método de pesquisa para a incorporação de eividências na saúde e enfermagem. Texto Contexto Enferm., v. 17, n. 4, p. 758-764, 2008.

RIESCO, M. L. G.; OLIVEIRA, S. M. J. V.; BONADIO, I. C.; SCHNECK, C. A.; SILVA, F. M. B.; DINIZ, C. S. G.; LOBO, S. F.; SAITO, E. Centros de Parto no Brasil: revisão da produção científica. Rev Esc Enferm USP, v. 43, n. Esp. 2, p. 1297-1302, 2009. Disponível em: <http://www. scielo.br/pdf/reeusp/v43nspe2/a26v43s2.pdf >. Acesso em: 04 jul. 2014.

SCHNECK, C. A.; GONZALEZ RIESCO, M. L.; BONADIO, I. C.; DINIZ, C. S. G.; OLIVEIRA, S. M. J. V. Resultados maternos e neonatais em centro de parto normal peri-hospitalar e hospital. Rev. Saúde Pública, São Paulo, v. 46, n. 1, feb. 2012. Disponível em: $\quad<$ http://www.scielo.br/scielo.php?script $=$ sci arttext\&pid $=$ S0034-89102012000100010 > . Acesso em: 09 set. 2014

SCHNECK, C. A.; RIESCO, M. L. G. Intervenções no parto de mulheres atendidas em um centro de parto normal intra-hospitalar. REME - Rev Min Enf., v. 10, n. 3, p. 240246, jul. 2006. Disponível em: < http://www.reme.org.br/ artigo/detalhes/413>. Acesso em: 01 maio 2014.

SILVA, B. F. M.; KOIFFMAN, M.D.; OSAVA, R. H.; OLIVEIRA, S. M. J.; GONZALEZ RIESCO, M.L. Centro de parto normal como estratégia de incentivo ao parto normal: estudo descritivo. Enfermería Global, n. 14, out. 2008. Disponível em: <http://revistas.um.es/eglobal/article/ viewFile/35921/34951 > . Acesso em: 19 maio 2014.

TORNQUIST, C. S. Armadilhas da nova era: natureza e maternidade no ideário da humanização do parto. Rev Estud Fem, v. 10, n. 2, jul./dez. 2002. Disponível em: $<$ http://www.scielo.br/pdf/ref/v10n2/14972>. Acesso em: 21 maio 2014.

Recebido em: 02 de dezembro de 2014 Aceito em: 08 de junbo de 2015

MENDES, K.D.S.; SILVEIRA, R.C.C.P.; GALVÃO, C.M. 